\title{
Critical appraisal and clinical utility of atosiban in the management of preterm labor
}

This article was published in the following Dove Press journal:

Therapeutics and Clinical Risk Management

14 April 2010

Number of times this article has been viewed

\author{
Olaleye Sanu' \\ Ronald F Lamont ${ }^{1-5}$ \\ 'Department of Obstetrics and \\ Gynaecology, St Mary's Imperial NHS \\ Trust, London, UK; ${ }^{2}$ Northwick Park \\ Institute of Medical Research, London, \\ UK; ' Imperial College, London, UK; \\ ${ }^{4}$ University College, London, UK; \\ ${ }^{5}$ Department of Obstetrics and \\ Gynecology, Wayne State \\ University, Detroit, MI, USA
}

\begin{abstract}
Preterm birth is the major cause of perinatal morbidity and mortality in the developed world, and spontaneous preterm labor is the commonest cause of preterm birth. Interventions to treat women in spontaneous preterm labor have not reduced the incidence of preterm births but this may be due to increased risk factors, inclusion of births at the limits of viability, and an increase in the use of elective preterm birth. The role of antibiotics remains unproven. In the largest of the randomized controlled trials, evaluating the use of antibiotics for the prevention of preterm births in women in spontaneous preterm labor, antibiotics against anaerobes and bacterial vaginosis-related organisms were not included, and no objective evidence of abnormal genital tract flora was obtained. Atosiban and nifedipine are the main tocolytic agents used to treat women in spontaneous preterm labor, but atosiban is the tocolytic agent with the fewest maternal - fetal side effects. A well conducted randomized controlled trial comparing atosiban with nifedipine for their effectiveness and safety is needed.
\end{abstract}

Keywords: preterm labor, preterm births, management, tocolytics, atosiban

\section{Introduction}

Spontaneous preterm labor (SPTL) - the onset of regular, painful, synchronous uterine contractions before 37 completed weeks of gestation - is a syndrome caused by a multifactorial etiology such as infection/inflammation, uteroplacental ischemia or hemorrhage, uterine overdistention, stress, and immunologically related conditions. ${ }^{1}$ SPTL is the most common cause of antenatal hospitalization, ${ }^{2}$ and of all preterm births (PTBs), about $40 \%$ to $50 \%$ are related to SPTL. ${ }^{3,4}$ In contrast to preterm premature rupture of the membranes and iatrogenic PTB, about $32 \%$ of all SPTL is associated with intra-amniotic infection (IAI). ${ }^{5}$ This article reviews the management of SPTL and the role of tocolytics.

\section{Diagnosis of SPTL}

The accurate diagnosis of SPTL is difficult. Fetal fibronectin (FFN), a glycoprotein found in the chorioamniotic membranes, decidua and cytotrophoblast is elevated in cervicovaginal secretions of women who deliver preterm. ${ }^{6}$ A multicenter trial of 763 women considered to be in SPTL, with a mean gestational age at sampling of $30.3 \pm 3.0$ weeks, evaluated the negative and positive predictive values of FFN for PTB. The mean gestational age at delivery was $38.4 \pm 2.6$ weeks, and at least $80 \%$ of these women remained undelivered up to 7 days later, irrespective of their FFN status. ${ }^{6}$ The negative predictive value of the FFN test far exceeds the positive predictive value. A meta-analysis of 27 studies using cervicovaginal FFN as a marker for preterm
Correspondence: Professor Ronald F Lamont

Department of Obstetrics and Gynecology, Wayne State University, Detroit, MI, USA

Email rlamont@med.wayne.edu 
delivery showed a low sensitivity for PTB occurring at less than 34 weeks' gestation. ${ }^{7}$ A Cochrane systematic review on the use of FFN testing for reducing the risk of PTB showed that management of women in SPTL, based on knowledge of FFN results versus no knowledge, significantly decreased the risk of PTB. ${ }^{8}$ It remains uncertain which interventions are most useful when a positive FFN test is obtained, but length of hospital stay might be reduced and unnecessary tocolytic therapy and in utero transfer prevented if a negative FFN is obtained. The combination of positive FFN test, and the transvaginal ultrasound scan (TVUSS) of women with a short cervical length $(<30 \mathrm{~mm})$ may identify those women who may benefit from interventions such as antibiotics and tocolytics which may reduce PTB. ${ }^{9-11}$

\section{Infection and PTL}

Chorioamnionitis is often subclinical, and requires amniocentesis to establish the diagnosis. ${ }^{12,13}$ Intraamniotic inflammation, defined as negative amniotic fluid (AF) culture with elevated levels of AF interleukin (IL)-1- $\alpha$, IL 1- $\beta$, IL-6, IL-8, tumor necrosis factor-alpha (TNF- $\alpha$ ) and IAI (positive AF culture) are both associated with an increased risk of adverse outcomes when compared with idiopathic SPTL. ${ }^{14-21}$ These include clinical chorioamnionitis, funisitis, neonatal respiratory distress syndrome (RDS), neonatal pneumonia, intraventricular hemorrhage ( $\geq$ grade II), bronchopulmonary dysplasia and periventricular leucomalacia, and cerebral palsy., ${ }^{5,22-27}$

\section{Antibiotics used in SPTL}

Randomized placebo-controlled trials of the use of antibiotics for the treatment of SPTL have yielded conflicting results. The inclusion of antibiotics (clindamycin or metronidazole) which have activity against anaerobes and bacterial vaginosis (BV)-related organisms resulted in prolongation of pregnancy. ${ }^{28-30}$ Using a combination of ampicillin and metronidazole, ${ }^{28}$ Svare et al demonstrated that there was a significant prolongation of pregnancy (admission to delivery 47.5 days versus 27 days, $P<0.05$ ) and decreased incidence of preterm birth $(42 \%$ versus $65 \% P<0.05)$. There was no significant effect on maternal and neonatal infection. Norman et al used ampicillin and metronidazole and showed that pregnancy was prolonged by at least 7 days compared to placebo $(63 \%$ versus $37 \%, P=0.03)$ and neonatal morbidity was also decreased. ${ }^{29}$ McGregor et al used clindamycin, and detected a statistically significant prolongation of pregnancy in the treated group compared to placebo (35 days versus 25 days $P=0.02) .{ }^{30}$
Oracle II randomized 6295 women into 4 groups erythromycin only, co-amoxiclav only, combination of erythromycin and co-amoxiclav, and placebo. The primary outcome measure was a composite of neonatal death, chronic lung disease or major cerebral abnormality on ultrasound before discharge from hospital. None of the antibiotics used showed any reduction in the composite outcome compared to placebo. There was no statistically significant difference in the prolongation of pregnancy between the four groups, ${ }^{31}$ but the antibiotics used are not active against BV-related organisms, ${ }^{32-34}$ and are not recommended for the treatment of $\mathrm{BV}^{35}$ In addition, no objective measure of abnormal colonization was used, and women with signs of infection were excluded. It is likely therefore, that a minority of women given antibiotics had any infection which needed correction. The median gestational age at delivery within the four groups was beyond 38 completed weeks which raises the question whether the women recruited were really in SPTL. In addition, other trials which did not use antibiotics which are active against BV related organisms and anaerobes have not shown any benefit. ${ }^{36-41}$ A Cochrane systematic review of eleven trials on the use of antibiotics for inhibiting PTL concluded that antibiotic use showed no benefit, ${ }^{42}$ partly because of small numbers of women included in the trials which used clindamycin or metronidazole compared to trials which did not use them, and mainly the overwhelming weighting of Oracle $\Pi$.

\section{Antenatal glucocorticoids and PTL}

Administration of a single course of antepartum glucocorticoids to women in SPTL at risk of PTB between 23 and 33 weeks gestation has been proven to reduce the incidences of neonatal RDS, intraventricular hemorrhage, neonatal sepsis, and need for admission to neonatal intensive care unit, necrotizing enterocolitis, and neonatal death. ${ }^{43}$ However, antenatal exposure to glucocorticoids might result in insulin resistance when the offspring reach adulthood. ${ }^{44}$ The benefit observed on the reduced incidence of neonatal RDS does not last beyond 7 days, which supports the importance of accurate diagnosis of SPTL. Repeat courses of antepartum glucocorticoids should be avoided since they can be associated with increased risk of small for gestational age, cesarean section, ${ }^{45}$ and suppression of the maternal and neonatal hypothalamic-pituitary-adrenal (HPA) axis. ${ }^{46,47}$ But the Cochrane review on repeat courses of antepartum glucocorticoids showed a reduction in occurrence and severity of any neonatal lung disease, and serious infant morbidity. ${ }^{45}$ In a retrospective analysis of 713 infants (369 and 134 singleton 
preterm infants delivered at $\leq 34$ and $\geq 35$ weeks gestation respectively, and 210 multiple gestation) whose mothers were exposed to single or multiple courses of antenatal corticosteroids (2-12 courses), a significant reduction in the head circumference $(4.6 \pm 1.9 \mathrm{~mm})$ was observed in the multiple course group. ${ }^{48} \mathrm{~A}$ cohort of 541 very preterm infants from singleton pregnancies between 3 and 6 years of age were evaluated, using physical, cognitive, and psychological assessments. Three or more courses of antenatal corticosteroids were associated with increased rates of aggressive/destructive, distractible, and hyperkinetic behavior. The rate of cerebral palsy was, however, reduced. ${ }^{49}$ Nevertheless, repeat courses of antepartum glucocorticoids should be avoided, and the single course should be selective and optimized.

\section{Pathophysiology/biochemical triggers of PTL}

The precise mechanism of labor in women remains incomplete clinically, endocrinologically and biochemically. Relatively increased plasma levels of corticotrophin releasing hormone - a peptide produced by the placenta - is associated with increased risk of PTBs, but this observation is not specific to SPTL ${ }^{50-54}$ Detection of an early surge or increased levels of salivary estriol is also associated with SPTL, but this surge can occur about 3 weeks before the onset of SPTL. ${ }^{51}$

Experiments on parturition in sheep show that activation of the fetal pituitary adrenal axis results in increased fetal cortisol secretion. Cortisol leads to activation of $\mathrm{p} 450$ dependent placental 17 alpha hydroxylase and 17-20 lyase enzymes to cause conversion of $\mathrm{C} 21$ to $\mathrm{C} 18$ steroids. ${ }^{56}$ Maternal estradiol levels rise, and progesterone levels fall, and this change in estrogen: progesterone ratio leads to increased production of prostaglandins (PGs). Consequently, there is cervical ripening and increased activation of oxytocin receptors, leading to myometrial contractility. However, neither the induction of the placental p450 enzymes nor the fall in progesterone levels has been demonstrated in humans. It is possible that the lack of expression in humans of the placental p450 C17 enzymes serves to maintain the placental production of progesterone, which is reponsible for uterine quiescence and regulation of uterine activity during pregnancy.

Ovine and primate parturition studies show that increased levels of intrauterine cortisol, of maternal, fetal or the fetoplacental origin induce the expression of PG synthase type 2 (PGHS-2) in the amniochorion, and the supression of the $\mathrm{NAD}^{+}-$dependent $\mathrm{PG}$ dehydrogenase in the amnion predominantly from epithelial cells, and to a lesser extent mesenchymal cells. As a result, there is increased production of PGE- $2,{ }^{58}$ and the increased activity of the fetal HPA axis leads to increased production of estriol which activates the PGHS-2 in maternal endometrial epithelium leading to increased levels of PGF2- $\alpha .^{57,59-61}$

In vitro studies on the regulation of PGHS-2 activity by glucocorticoids in the amnion have yielded conflicting results. Dexamethasone increases the PGHS-2 activity in confluent amnion cell cultures, ${ }^{62}$ and has no effect on PGHS-2 activity in freshly cultured amnion cells. ${ }^{63}$ In addition, dexamethasone suppressed cytokine induced PGHS- $\Pi$ expression and activity in amnion cells by blocking transcription factor binding at the nuclear factor kappa beta (NF- $\kappa \beta)$ and CRE 5 promoter sequences of the PGHS-2 gene. ${ }^{64}$

\section{The role of progesterone}

The suppression of progesterone receptors (PR) - effectively a functional withdrawal of progesterone - is also linked to the initiation of labor in humans. Two types of PR (A and B) are expressed in the human myometrium at term. It is the expression of PR-A mRNA, relative to PR-B mRNA that leads to functional withdrawal of progesterone. ${ }^{65}$ In vitro studies in mice demonstrate increased transcriptional activities of NF- $\kappa \beta$, in response to inflammatory cytokines such as IL- $1 \beta$ produced by fetal macrophages. Activation of fetal macrophages is believed to be due to secretion into the AF of major lung surfactant protein A and the final effect of these activities is supression of the PR. ${ }^{66}$

In an in vitro study of human tissue, Allport et $a{ }^{67}$ showed that increased NF- $\kappa B$ transcriptional activity leads to activation of the cyclooxygenase (COX) enzyme in the amnion. Two isoforms, one constitutive (COX-1) and the other inducible (COX-2) exist, but in human labor it is the COX-2 enzyme that converts free arachidonic acid (produced from glycophospholipids in the cell membrane by increased phospholipase activity) into the PG precursors - PGH-2 and PGG-2. ${ }^{68,69}$ Triggers such as increased cortisol from maternal or fetal stress and/or inflammatory cytokines lead to increased production of $\mathrm{PGs}$ which override uterine quiescence, leading to functional withdrawal of progesterone.

\section{Role of oxytocin}

Coupling of oxytocin (OT), endothelin or prostanoid receptors with the enzyme phosholipase $\mathrm{C}$ beta (PLC- $\beta$ ) through the $G$ protein coupled receptors (the most abundant receptors in the uterus) hydrolyzes OT sensitive phosphatidylinositol 4, 5 bisphosphate (PIP2) in the cell membrane..$^{58}$ This process 
generates two secondary messengers - inositol 1, 4, 5 triphosphate (IP3) and diacyl glycerol. IP3, coupled with specific receptors, releases stored intracellular calcium from the sacroplasmic reticulum. Production of IP3 may further induce influx of calcium $\left(\mathrm{Ca}^{2+}\right)$ from the extracellular space through voltage gated channels. ${ }^{70}$ Activated myosin light chain kinase, under the influence of released intracellular calcium - calmodulin complexes, causes phosphorylation of myosin which then interacts with actin to cause uterine contraction. Dephosphorylation of myosin by myosin phosphatase leads to uterine relaxation. ${ }^{58,70}$

The Rho kinases, which belong to the family of G-proteins, also cause uterine contractions by inhibiting myosin phosphatase activity, which leads to calcium sensitization. ${ }^{71}$ In contrast, coupling of $\beta_{2}$-adrenergic and prostanoid receptors with the enzyme adenylcyclase (AC), possibly through G-protein coupled receptors, lead to production of cyclic nucleotides (cAMP and cGMP) and promotes uterine relaxation. ${ }^{58,72}$ Phosphodiesterase (PDE)-4, an isozyme of PDE predominantly expressed in the pregnant uterus, inhibits cAMP production, but progesterone promotes $\mathrm{AC}$ and inhibits PDE-4 activity. ${ }^{73}$ Summary of some of these biochemical events leading to PTL are shown in Figure 1.

\section{Role of tocolytics - atosiban}

OT is a potent uterotonic hormone that is secreted from the posterior pituitary gland. Although increased levels of OT are not evident during labor, the uterine contractile effect of oxytocin relies on activated OT receptors in the presence of increased estrogen and PG production. ${ }^{74}$ Atosiban is a nonapeptide, desamino-OT analogue, and a competitive vasopressin/oxytocin receptor antagonist (VOTra). ${ }^{75-78}$ Atosiban inhibits the OT-mediated release of IP3 from the myometrial cell membrane. ${ }^{75}$ As a result, there is reduced release of intracellular, stored calcium from the sacroplasmic reticulum of myometrial cells, and reduced influx of $\mathrm{Ca}^{2+}$ from the extracellular space through voltage gated channels. In addition, atosiban suppresses OT-mediated release of PGE and PGF from the decidua. ${ }^{79,80}$

\section{Phase II and III studies}

Peak plasma concentrations of atosiban was achieved at 2 to 8 minutes following intravenous (IV) administration (10 nmol/kg body weight) compared to peak concentration at 10 to 45 minutes following intranasal administration of atosiban at $100 \mathrm{nmol} / \mathrm{kg}$ body weight. ${ }^{81}$ Goodwin et al showed that following IV infusion of atosiban $(300 \mu / \mathrm{min})$ in women between 20 and 36 weeks' gestation, and in whom contractions were absent for 6 hours or maximum infusion length of 12 hours, plasma atosiban concentrations reached steady state within 1 hour of the start of IV infusion. ${ }^{82}$ The decrease in uterine activity in the first 4 hours of IV infusion was directly proportional to the duration of infusion. At the completion of infusion, plasma atosiban levels declined in a bi-exponential manner with initial and terminal half lives of $13 \pm 3$ and $102 \pm 18$ minutes, respectively. In a phase II randomized placebo controlled trial of the effect of atosiban on premature uterine activity (20 to 36 weeks gestation), a 2-hour infusion of atosiban led to a statistically significant decline in the frequency of uterine contractions, suggesting that OT plays a role in the maintenance of PTL. The only adverse outcome reported in the atosiban group was nausea and vomiting in one patient. ${ }^{83}$ In a phase III randomized controlled trial of the effect of atosiban on PTL (20 to 34 weeks), which allowed tocolytic rescue if after 1 hour of atosiban or placebo infusion, premature labor continued, the primary end-point was the time to delivery or therapeutic failure (progression of labor requiring an alternative tocolytic). There was no statistically significant difference between the two groups for the primary end-point. The secondary endpoints were the proportions of women who were successfully treated at 24 hours, 48 hours and 7 days after commencing atosiban or placebo infusion. The proportions were significantly higher in the atosiban group: $73 \%$ versus $58 \%$ at 24 hours $(P<0.001), 67 \%$ versus $56 \%$ at 48 hours $(P=0.008)$, and $62 \%$ versus $49 \%$ at 7 days $(P=0.003)$. Compared to placebo, the effect of atosiban on prolongation of pregnancy up to 7 days was more evident in pregnancies $\geq 28$ weeks completed weeks of gestation; $65 \%$ versus $48 \%$, and $51 \%$ versus $59 \%$ at $<28$ weeks. ${ }^{84}$ These findings emphasize the fact that VOTras play a role in the maintenance of SPTL, yet other mechanisms are also involved. The perinatal mortality rate was $2.1 \%$ in the atosiban group, compared to $1.4 \%$ in the placebo group with or without tocolytic rescue. ${ }^{84}$ However, the randomization was not stratified according to gestational age, which resulted in an excess of extremely premature infants at a more advanced stage of labor in the atosiban group, and the Cochrane Review ${ }^{85}$ has been criticized for their use of these data. ${ }^{77}$ In a randomized controlled trial of women who, after successful treatment with atosiban, had a maintenance subcutaneous infusion of atosiban or placebo, the use of atosiban resulted in a statistically significant prolongation of uterine quiescence, compared to placebo (median of 32.6 days versus 27.6 days). Women in the atosiban group had higher incidence injection site reactions (70\% versus $48 \%$ ) during the maintenance treatment. ${ }^{86}$ 
compared to atosiban. However, the number of women who remained undelivered by 48 hours was not statistically significantly different between the two groups. ${ }^{88}$ The true effect of randomization can be lost when comparing the effectiveness of two tocolytics in this indirect way, and the authors acknowledged the shortcomings of such an analysis and that a number of assumptions were made in the comparisons. A small interventional randomized controlled trial, of 63 women, comparing atosiban with nifedipine for the treatment of SPTL (24 weeks to 35 weeks gestation) permitted tocolytic rescue after 1 hour for failed tocolysis by the assigned drug. Tocolytic agents were administered until uterine quiescence was achieved, and maintenance tocolytic regimes were not specified. The main outcome measure was the proportion of women who did not deliver, or who required alternative tocolytic therapy to avoid side effects 48 hours and 7 days after initiation of treatment. The study showed that there was no statistically significant difference between the two groups in delay of delivery for 48 hours up to 7 days. There was no statistically significant difference between the groups in the need for rescue tocolytic therapy. Nifedipine achieved uterine quiescence faster than atosiban (mean of 2.2 hours \pm 0.93 versus 4.2 hours \pm 1.1 ). Nausea occurred more frequently in the atosiban group. Headache, flushing, palpitation and hypotension were significantly increased in the nifedipine goup. Perinatal and neonatal outcomes were not significantly different between the groups. ${ }^{89}$ Another randomized controlled trial of 80 women, compared the efficacy of atosiban and nifedipine for the delay of delivery in women with PTL between 26 weeks and 34 completed weeks of gestation. Atosiban was as effective as nifedipine for delay of delivery for 48 hours and 7 days, and with minimal maternal side effects. Rescue tocolytic and maintenance therapy were not part of the protocol. Hypotension $(27.5 \%)$, palpitations (7.5\%) and maternal tachycardia $(7.5 \%)$ were reported in the nifedipine group and none $(0 \%)$ in the atosiban group..$^{90}$

\section{Adverse effects of tocolytics}

The posterior pituitary hormones, OT and arginine vasopressin, differ in structure by only two amino acids, and atosiban influences physiological effects of arginine vasopressin on the feto-maternal cardiovascular and renal systems. ${ }^{91}$ In late-gestation sheep, the administration of atosiban for 1 hour failed to induce fetomaternal cardiovascular changes. ${ }^{92} \mathrm{IV}$ atosiban $(300 \mu \mathrm{g} / \mathrm{min})$ used in women scheduled for elective cesarean section demonstrated no significant effect on the umbilical cord blood gases, and maternal hematocrit. ${ }^{93}$ In contrast Blea et al found that in pregnant ewes, IV nifedipine was associated with fetal hypoxia and acidosis. ${ }^{94}$ There are also concerns with respect to the number of published reports of adverse feto-maternal events after the use of CCBs, compared to the use of atosiban. ${ }^{95-107}$ In children aged 9 to 12 years who were exposed to nifedipine in utero compared to others with in utero exposure to ritodrine, measures of behavioural-emotional problems, motor function, parenting problems and education failed to demonstrate any significant difference between the two groups. The same comparison is needed to evaluate the long-term outcomes in children exposed to atosiban in utero, compared to nifedipine. ${ }^{108}$

For the treatment of SPTL, a complete course of atosiban is much more expensive than that of nifedipine. ${ }^{109}$ There is no doubt that a well conducted randomized controlled trial of atosiban versus nifedipine is needed. ${ }^{110}$

\section{Conclusion}

PTL is the most common event leading to PTB, but the prevention of SPTL remains challenging for clinicians. Accurate prediction of PTB in women admitted with threatened preterm labor remains difficult. Compared to traditional clinical methods, the combination of TVUSS and FFN may identify women who are in SPTL, and who are at increased risk of PTB, but further research is needed to identify factors that have better positive predictive values. The role of antibiotics for the prevention of PTB in women in SPTL remains unproven, but this should not be confused with prophylactic antibiotics given to women with abnormal genital tract colonization in early pregnancy. Studies that identify women with subclinical IAI may reveal women who are more likely to benefit from appropriate antibiotic administration. Tocolytic therapy is relatively ineffective in SPTL because of infection, and should be reserved for those in SPTL, of no obvious infective etiology. Compared to betaagonists and CCBs, atosiban has the fewest maternal and fetal side effects. Unlike CCBs, atosiban has proven benefit over placebo, and is at least as effective as other tocolytics. The role of atosiban for the prevention of PTB in women with SPTL without subclinical IAI, and in gestations when VOTra are well established ( $>28$ weeks' gestation) needs further evaluation. Such study should include protocols to identify women likely to be in SPTL using FFN and TVUSS of cervical length.

\section{Disclosures}

The authors declare no conflicts of interest. 


\section{References}

1. Romero R, Espinoza J, Kusanovic JP, et al. The preterm parturition syndrome. BJOG. 2006;113(Suppl 3):17-42.

2. Savita DA, Blackmore CA, Thorp JM. Epidemiologic characteristics of preterm Delivery: etiology heterogeneity. Am J Obstet Gynecol. 1991;467-471.

3. Tucker JM, Goldenberg RL, Davis RO, Cooper RL, Winker CL, Hauth JC. Etiologies of preterm birth in an indigent population: is prevention a logical expectation? Obstet Gynecol. 1991;77:343-347.

4. Martin JA, Hamilton BE, Sutton PD, et al. Births: final data for 2005. Natl Vital Stat Rep. 2007;56:1-103.

5. Yoon BH, Romero R, Moon JB, et al. Clinical significance of intraamniotic inflammation in patients with preterm labor and intact membranes. Am J Obstet Gynecol. 2001;185:1130-1136.

6. Peaceman AM, Andrews WW, Thorp JM, et al. Fetal fibronectin as a predictor of preterm birth in patients with symptoms: a multicenter trial. Am J Obstet Gynecol. 1997;177:13-18.

7. Leitich H, Egarter C, Kaider A, Hohlagschwandtner M, Berghammer P, Husslein P. Cervicovaginal fetal fibronectin as a marker for preterm delivery: A meta-analysis. Am J Obstet Gynecol. 1999;180:1169-1176.

8. Berghella V, Hayes E, Visintine J, Baxter J. Fetal fibronectin testing for reducing the risk of preterm birth. Cochrane Database Syst Rev. 2008; Issue 4.

9. Gomez R, Romero R, Medina L, et al. Cervicovaginal fibronectin improves the prediction of preterm delivery based on sonographic cervical length in patients with preterm uterine contractions and intact membranes. Am J Obstet Gynecol. 2005;192:350-359.

10. Ness A, Visintine J, Ricci E, Boyle K, Berghella V. Use of fetal fibronectin and transvaginal ultrasound cervical length to triage women with suspected preterm labor: A randomised trial. Am J Obstet Gynecol. 2006;195(6 Suppl 1):S67.

11. Ness A, Visintine J, Ricci E, et al. Does Knowledge of cervical length and fetal fibronectin affect the management of women with threatened preterm labour? A randomised trial. Am J Obstet Gynecol. 2007;197:426.e1-426.e7.

12. Allbert JR, Naef RW, Perry KG, Magann EF, Whitworth NS, Morrison JC. Amniotic fluid interleukin-6 and interleukin-8 levels predict the success of tocolysis in patients with preterm labor. $J$ Soc Gynecol Invest. 1994;1:264-268.

13. Gibbs RS, Romero R, Hillier SL, Eschenbach DA, Sweet RL. A review of premature birth and subclinical infection. Am J Obstet Gynecol. 1992;166:1515-1528.

14. Romero R, Mazor M, Wu YK, et al. Infection in the pathogenesis of preterm labor. Semin Perinatol. 1988;12:262-279.

15. Romero R, Sirtori M, Oyarzun E, et al. Infection and labor. V. Prevalence, microbiology, and clinical significance of intraamniotic infection in women with preterm labor and intact membranes. $\mathrm{Am} J$ Obstet Gynecol. 1989;161:817-824.

16. Gonclaves LF, Chaiworapongsa T, Romero R. Intrauterine infection and prematurity. Ment Retard Dev Disabil Res Rev. 2002;8:3-13.

17. Gomez R, Ghezzi F, Romero R, Munoz H, Tolosa JE, Rojas I. Premature labor and intra-amniotic infection. Clinical aspects and role of cytokines in diagnosis and pathophysiology. Clin Perinatol. 1995;22:281-342.

18. Romero R, Durum SK, Dinarello CA, et al. Interleukin-1: a signal for the initiation of labour in chorioamnionitis. 33rd Annual Meeting for the Society for Gynecologic Investigation, 19-22 March 1986, Toronto, Ontario Canada.

19. Romero R, Manogue KR, Mitchell MD, et al. Cachectin-tumour necrosis factor in the amniotic fluid of women with intraamniotic infection and preterm labor. Am J Obstet Gynecol. 1989;161:336-341.

20. Gravett MG, Witkin SS, Haluska GJ, Edwards JL, Cook MJ, Novy MJ. An experimental model for intraamniotic infection and preterm labor in rhesus monkeys. Am J Obstet Gynecol. 1994;171:1600-1667.

21. Coultrip LL, Lien JM, Gomez R, Kapernick P, Khoury A, Grossman JH. The value of amniotic fluid interleukin-6 determination in patients with preterm labor and intact membranes in the detection of microbial invasion of the amniotic cavity. Am J Obstet Gynecol. 1994;171:901-911.
22. Yoon BH, Romero R, Kim CJ, et al. Amniotic fluid interleukin-6: a sensitive test for antenatal diagnosis of acute inflammatory lesions of preterm placenta and prediction of perinatal morbidity. Am J Obstet Gynecol. 1995;172:960-970.

23. Yoon BH, Romero R, Kim CJ, et al. High expression of tumour necrosis factor- $\alpha$ and interleukin- 6 in periventricular leukomalacia. Am J Obstet Gynecol. 1997;177:406-411.

24. Yoon BH, Jun JK, Romero R, et al. Amniotic fluid inflammatory cytokines (interleukin-6, interleukin 1- $\beta$, and tumour necrosis factor- $\alpha$ ), neonatal brain white matter lesions, and cerebral palsy. Am J Obstet Gynecol. 1997;177:19-26.

25. Martinez E, Figueroa R, Garry D, et al. Elevated amniotic fluid interleulin-6 as a predictor of neonatal periventricular leukomalacia and intraventricular hemorrhage. J Matern Fetal Invest. 1998;8:101-107.

26. Hitti J, Tarczy-Hornoch P, Murphy J, Hillier SL, Aura J, Eschenbach DA. Amniotic fluid infection, cytokines and adverse outcome among infants at 34 weeks' gestation or less. Obstet Gynecol. 2001;98:1080-1088.

27. Challis JR, Lye SJ, Gibb W, Whittle W, Patel F, Alfaidy N. Understanding preterm labor. Ann N Y Acad Sci. 2001;943:225-234.

28. Svare J, Langhoff-Roos J, Andersen L, et al. Ampicillin-metronidazole treatment in idiopathic preterm labor: a randomised controlled multicentre trial. BJOG. 1997;104:892-897.

29. Norman K, Pattinson RC, de Souza J, de Jong P, Moller G, Kirsten G. Ampicillin and metronidazole treatment in preterm labor: a multicentre, randomised controlled trial. BJOG. 1994;101:404-408.

30. Mcgregor JA, French JI, Seo K. Adjunctive clindamycin therapy for preterm labor: results of a double-blind, placebo-controlled trial. Am J Obstet Gynecol. 1991;165:867-875.

31. Kenyon SL, Taylor DJ, Tarnow-Mordi W. Broad-spectrum antibiotics for spontaneous preterm labor: the ORACLE 11 randomised trial. Lancet. 2001;357:991-996.

32. Lamont RF. Can antibiotics prevent preterm birth-pro and con debate. BJOG. 2005;112:67-73.

33. Lamont RF. Antibiotics used in women at risk of preterm birth. Am J Obstet Gynecol. 2008;199:583-584.

34. Lamont RF. Association between cerebral palsy and erythromycin. Lancet. 2009;373:26.

35. Workowski KA, Berman SM. Sexually transmitted disease treatment guidelines. MMWR Recomm Rep. 2006;55:1-94.

36. Newton ER, Dinsmoor MJ, Gibbs RS. A randomised, blinded, placebocontrolled trial of antibiotics in idiopathic preterm labor. Obstet Gynecol. 1989;74:562-566.

37. Newton ER, Shields L, Ridgway LE, Berkus MD, Elliott BD. Combination antibiotics and indomethacin in idiopathic preterm labor: a randomised double blind clinical trial. Am J Obstet Gynecol. 1991;165:1753-1759.

38. Romero R, Sibai B, Caritis S, et al. Antibiotic treatment of preterm labour with intact membranes: a multicenter, randomised, double blind, placebo-controlled trial. Am J Obstet Gynecol. 1993;169:764-774.

39. Gordon M, Samuels P, Shubert P, Johnson F, Gebauer C, Iams J. A randomised, prospective study of adjunctive ceftizoxime in preterm labor. Am J Obstet Gynecol. 1995;172:1546-1552.

40. Oyarzun E, Gomez R, Rioscco A, Gonzalez P, Gutierrez P, Donoso E, et al. Antibiotic treatment in preterm labor and intact membranes: a randomised, double-blinded, placebo-controlled trial. J Matern Fetal Med. 1998;7:105-110.

41. Cox SM, Boham V, Sherman ML, Leveno KJ. Single-center randomized placebo controlled trial of antimicrobials for prevention of preterm birth. Am J Obstet Gynecol. 1996;174:206-210.

42. King JF, Fenady V, Murray L. Prophylactic antibiotics for inhibiting preterm labour with intact membranes. Cochrane Database Syst Rev. 2002;(4):CD000246.

43. Roberts D, Dalziel SR. Antenatal corticosteroids for accelerating fetal lung maturation for women at risk of preterm birth. Cochrane Database Syst Rev. 2006;(3):CD004454.

44. Daiziel SR, Walker NK, Parag V, et al. Cardiovascular risk factors after antenatal exposure to betamethasone: 30-year follow-up of a randomised controlled trial. Lancet. 2005;365:1856-1862. 
45. Crowther CA, Harding JE. Repeat doses of prenatal corticocteroids for women at riak of preterm birth for preventing neonatal respiratory disease. Cochrane Database Syst Rev. 2007;(3):CD003935.

46. Mckenna DS, Witber GM, Nagaraja HN, Samuels P. The effects of repeat doses of antenatal corticosteroids on maternal adrenal function. Am J Obstet Gynecol. 2000;183:669-673.

47. Ashwood PJ, Crowther CA, Willson KJ, et al. Neonatal adrenal function after repeat dose prenatal corticosteroids: a randomised controlled trial. Am J Obstet Gynecol. 2006;194:861-867.

48. Abbassi S, Hirsch D, Davis J, et al. Effect of single versus multiple courses of Antenatal corticosteroids on maternal and neonatal outcome. Am J Obstet Gynecol. 2000;182:1243-1249.

49. French NP, Hagan R, Evans SF, Mullan A, Newnham JP. Repeated antenatal corticosteroids: effects on cerebral palsy and childhood behaviour. Am J Obstet Gynecol. 2004;190:588-595.

50. Ohrlander S, Gennser G, Eneroth P. Plasma cortisol levels in human fetus during parturition. Obstet Gynecol. 1976;48:381-387.

51. McGregor JA, Jackson GM, Lachelin GC, et al. Salivary estriol as risk assessment for preterm labor: a prospective trial. Am J Obstet Gynecol. 1995;4:1337-1342.

52. McLean M, Bisits A, Davies J, Woods R, Lowry P, Smith R. A placental clock controlling the length of human pregnancy. Nat Med. 1995;1:460-463.

53. Sandman CA, Glynn L, Dunkel Schetter C, et al. Elevated maternal cortisol early in pregnancy predicts third trimester levels of placental corticotrophin releasing hormone $(\mathrm{CRH})$ : Priming the placental clock. Peptides. 2006;27:1457-1463.

54. Smith R, Smith JI, Shen X, et al. Patterns of plasma corticotrophinreleasing hormone, progesterone, oestradiol, and oestriol change and the onset of human labor. J Clin Endocrinol Metab. 2009;94:2066-2074.

55. Liggins GC. Parturition in the sheep and the human. Basic Life Sci. 1974;4:423-443.

56. Anderson AB, Flint AP, Turnbull AC. Mechanism of action of glucocorticoids in induction of ovine parturition: effect on placental steroid metabolism. J Endocrinol. 1975;66:61-70.

57. Whittle WL, Patel FA, Alfaidy N, et al. Glucocorticoid regulation of human and ovine parturition: the relationship between fetal hypothalamic-pituatary-adrenal axis activation and intrauterine prostaglandin production. Biol Reprod. 2001;64:1019-1032.

58. Lopez Bernal A. Mechanisms of labour - biochemical aspects. BJOG. 2003;110:39-45.

59. Novy MJ. Endocrine and pharmacological factors which influence the onset of Labour in rhesus monkeys. Ciba Found Symp. 1997;47: 259-295.

60. Mecanas C, Giussani D, Owiny JR, et al. Production of premature delivery in rhesus monkeys by androstenedione infusion. Nat Med. 1996;2:443-448.

61. Halushka GJ, Cook MJ, Novy MJ. Pulsatile infusion of ACTH into the fetal circulation in rhesus monkeys leads to premature labour and delivery. J Soc Gynecol Invest. 1999;6:61(abstract 66).

62. Whittle WL, Gibb W, Shallis JRG. The characterization of human amnion epithelial and mesenchymal cells: cellular expression, activity and glucocorticoid regulation of prostaglandin output. Placenta. 2000;21:394-401.

63. Gibb W, Breton R. Studies on the action of dexamethasone on prostaglandin output by freshly dispersed amnion cells. Acta Endocrinol (Copenh). 1993;8:563-567.

64. Wang Z, Tai HH. Interleukin-1b and dexamethasone regulate gene expression of prostaglandin $\mathrm{H}$ synthase-2 via the NFKB pathway in human amnion WISH cells. Prostaglandins Leukot Essent Fatty Acids. 1998;59:63-69.

65. Mesiano S, Chan EC, Fitter JT, et al. Progesterone withdrawal and oestrogen activation in human parturition are coordinated by progesterone receptor A expression in the myometrium. J Clin Endocrinol Metab. 2002;87:2924-2930.

66. Mendelson CR, Condon JC. New insights into the molecular endocrinology of parturition. J Steroid Biochem Mol Biol. 2005;93:113-119.
67. Allport VC, Pieber D, Slater DM, et al. Human labour is associated with nuclear factor-kB activity which mediates cyclo-oxygenase- 2 expression and is involved with 'functional progesterone withdrawal'. Mol Human Reprod. 2001;7:581-586.

68. Lindstrom TM, Bennett PR. The role of nuclear factor kappa B in human labour: Reproduction. 2005;130:569-581.

69. Mitchell MD. Regulation of eicosanoid biosynthesis during pregnancy and parturition. In: Hillier K, editor. Eicosanoids and Reproduction. Lancaster: MTP Press; 1987.

70. Arthur P, Taggart MJ, Mitchell BF. Oxytocin and parturition: a role for increased myometrial calcium and calcium sensitisation? Front Biosci. 2007;12:619-633.

71. Moran CJ, Friel AM, Smith TJ, Cairns M, Morrison JJ. Expression and modulation of Rho kinase in human pregnant myometrium. Mol Hum Reprod. 2002;8:196-200.

72. Europe-Finner GN, Phaneuf S, Tolkovsky AM, Watson SP, Lopez Bernal A. Down-regulation of $\mathrm{G}$ alpha $\mathrm{s}$ in human myometrium in term and preterm labor: a mechanism for parturition. J Clin Endocrinol Metab. 1994;79:1835-1839.

73. Mehats C, Tanguy B, Paris B, et al. Pregnancy induces a modulation of the cAMP phosphodiesterase 4-conformers ratio in human myometrium: consequences for the utero-relaxant effect of PDE4-selective inhibitors. J Pharmacol Exp Ther. 2000;292:817-823.

74. Oxytocin receptors in pregnant human uterus and regulation of oxytocin action during pregnancy and parturition. Am J Obstet Gynecol. 1984;150:138-143.

75. Kam KYR, Lamont RF. Developments in the pharmacotherapeutic management of spontaneous preterm labor. Expert Opin Pharmacother. 2008;9:1153-1168.

76. Lamont RF. The development and introduction of anti-oxytocic tocolytics. BJOG. 2003;110(Suppl 20):108-112.

77. Lyndrup J, Lamont RF. The choice of tocolytic for the treatment of preterm labour: a critical evaluation of nifedipine versus atosiban. Expert Opin Investig Drugs. 2007;16:843-853.

78. Lamont RF, Kam KYR. Atosiban for the treatment of spontaneous preterm labor. Expert Rev Obstet Gynecol. 2008;3:163-174.

79. Jenkin G. Oxytocin and prostaglandin interactions in pregnancy and at parturition. J Reprod Fertil Suppl. 1992;45:97-111.

80. Husslein P, Fuchs AR, Fuchs F. Oxytocin and the initiation of human parturition. 11. Stimulation of prostaglandin production in human deciduas by oxytocin. Am J Obstet Gynecol. 1981;141:694-697.

81. Lundin S, Akerlund M, Fagerstrom PO, Hauksson A, Melin P. Pharmacokinetics in the human of a new synthetic vasopressin and oxytocin uterine antagonist. Acta Endocrinol (Copenh). 1986;112: 465-472.

82. Goodwin TM, Millar L, North L, Abrams LS, Weglein RC, Holland ML. The pharmacokinetics of the oxytocin antagonist atosiban in pregnant women with preterm uterine contractions. Am J Obstet Gynecol. 1995;173:913-917.

83. Goodwin TM, Paul R, Silver H, et al. The effect of the oxytocin antagonist atosiban on preterm uterine activity in the human. Am J Obstet Gynecol. 1994;170:474-478.

84. Romero R, Sibai BM, Sanchez-Ramos L, et al. An oxytocin receptor antagonist (atosiban) in the treatment of preterm labor: a randomized, double-blind, placebo-controlled trial with tocolytic rescue. Am JObstet Gynecol. 2000;182:1173-1183.

85. Papatsonis D, Flenady V, Cole S, Liley H. Oxytocin receptor antagonists for inhibiting preterm labor. Cochrane Database Syst Rev. 2005; Issue 3.

86. Valenzuela GJ, Sanchez-Ramos L, Romero R, et al. Maintenance treatment of preterm labor with the oxytocin antagonist atosiban. The Atosiban PTL-098 Study Group. Am J Obstet Gynecol. 2000;18: 1184-1190.

87. Moutquin JM, Cabrol D, Fisk NM. Effectiveness and safety of the oxytocin antagonist atosiban versus beta-adrenergic agonists in the treatment of preterm labour. The Worldwide Atosiban versus Beta-agonists Study Group. BJOG. 2001;108:133-142. 
88. Coomarasamy A, Knox EM, Gee H, Song F, Khan KS. Effectiveness of nifedipine versus atosiban for tocolysis in preterm labour: a meta-analysis with an indirect comparison of randomised trials. BJOG. 2003;110:1045-1049.

89. Al-Omari WR, Al-Shammaa HB, Al-Tikriti EM, Ahmed KW. Atosiban and nifedipine in acute tocolysis: a comparative study. Eur J Obstet Gynecol Reprod Biol. 2006;128:129-134.

90. Kashanian M, Akbarian AR, Soltanzadeh M. Atosiban and nifedipin for the treatment of preterm labor. Int J Gynecol Obstet. 2005;91:10-14.

91. Ervin MG. Perinatal fluid and electrolyte regulation: role of arginine vasopressin. Semin Perinatol. 1998;12:134-142.

92. Greig PC, Massmann GA, Demarest KT, et al. Maternal and fetal cardiovascular effects and placental transfer of the oxytocin antagonist atosiban in late-gestation pregnant sheep. Am J Obstet Gynecol. 1993;169:897-902.

93. Valenzuela GJ, Craig J, Bernhardt MD, Holland ML. Placental passage of the oxytocin antagonist atosiban. Am J Obstet Gynecol. 1995;172:1304-1306.

94. Blea CW, Barnard JM, Magness RR, Phernetton TM, Hendricks SK. Effect of nifedipine on fetal and maternal hemodynamics and blood gases. Am J Obstet Gynecol. 1997;176:922-930.

95. Oei SG, Oei SK, Brolmann HA. Myocardial infarction during nifedipine therapy for preterm labor. N Engl J Med. 1999;340:154.

96. Vaast P, Dubreuq-Fossaert S, Houfflin-Debarge V, et al. Acute pulmonary oedema during nicardipine therapy for premature labour; report of five cases. Eur J Obstet Gynecol Reprod Biol. 2004;113:98-99.

97. Vahaert D, Van AR. Acute myocardial infarction during pregnancy. Acta Cardiol. 2004;111:380-381.

98. Hodges R, Barkehall-Thomas A, Tippett C. Maternal hypoxia associated with nifedipine for threatened preterm labour. BJOG. 2004;111: 380-381.

99. Bal L, Thierry S, Brocas E, et al. Pulmonary edema induced by calciumchannel blockade for tocolysis. Anesth Analg. 2004;99:910-911.
100. Impey L. Severe hypotension and fetal distress following sublingual administration of nifedipine to a patient with severe pregnancy-induced hypertension at 33 weeks. BJOG. 1993;100:959-961.

101. Van Veen AJ, Pelinck MJ, Van Pampus MG, Erwich JJ. Severe hypotension and fetal death due to tocolysis with nifedipine. BJOG 2005;112:509-510.

102. Parasurraman R, Gandhi MM, Liversedge NH. Nifedipine tocolysis associated atrial fibrillation responds to DC cardioversion. BJOG. 2006;113:844-845.

103. Johnson KA, Mason GC. Severe hypotension and fetal death due to tocolysis with nifedipine. BJOG. 2005;112:1583.

104. Kandysamy V, Thompson AJ. Severe hypotension and fetal death due to tocolysis with nifedipine. BJOG. 2005;112:1582-1584.

105. Donders GG, Van Keirsbilick J, De Roo T, Schreven L, Hanssens M. Non-cardiogenic lung edema in a woman treated with atosiban for preterm labor. J Perinat Med. 2008;36:455-457.

106. Lamont RF. Commentary: A case of non-cardiogenic lung edema in a woman treated with atosiban for preterm labor. $J$ Perinat Med. 2008;36:458-459.

107. Khan K, Zamora J, Lamont RF, et al. Safety concerns for the use of calcium channel blockers in pregnancy for the treatment of spontaneous preterm labour and hypertension: a systematic review and meta-regression analysis. J Matern Fetal Neonatal Med. 2010 Feb 25. [Epub ahead of print].

108. Houtzager BA, Hogendoorn SM, Papatsonis DNN, et al. Long-term follow up of children exposed in-utero to nifedipine or ritodrine for the management of preterm labour. BJOG. 2006;113:324-331.

109. British National Formulary website: http://bnf.org. Accessed September 2009.

110. Lamont RF, Khan KS, Beattie B, et al. The quality of nifedipine studies used to assess tocolytic efficacy: a systematic review. J Perinat Med. 2005;33:287-295.
Therapeutics and Clinical Risk Management

\section{Publish your work in this journal}

Therapeutics and Clinical Risk Management is an international, peerreviewed journal of clinical therapeutics and risk management, focusing on concise rapid reporting of clinical studies in all therapeutic areas, outcomes, safety, and programs for the effective, safe, and sustained use of medicines. This journal is indexed on PubMed Central, CAS,

\section{Dovepress}

EMBase, Scopus and the Elsevier Bibliographic databases. The manuscript management system is completely online and includes a very quick and fair peer-review system, which is all easy to use. Visit http://www.dovepress.com/testimonials.php to read real quotes from published authors.

Submit your manuscript here: http://www.dovepress.com/therapeutics-and-clinical-risk-management-journal 